\title{
Prediction of the reduced glutathione (GSH) reactivity of dental methacrylate monomers using NMR spectra - Relationship between toxicity and GSH reactivity
}

\author{
Seiichiro FUJISAWA ${ }^{1}$ and Yoshinori KADOMA ${ }^{2}$ \\ ${ }^{1}$ Meikai University School of Dentistry, 1-1 Keyakidai, Sakado, Saitama 350-0283, Japan \\ ${ }^{2}$ Institute of Biomaterials and Bioengineering, Tokyo Medical and Dental University, 2-3-10 Kanda-Surugadai, Chiyoda-ku, Tokyo 101-0062, Japan \\ Corresponding author, Seiichiro FUJISAWA; E-mail: fujisawa33@nifty.com
}

\begin{abstract}
It has been established that the toxicity of acrylate and methacrylate monomers is driven by their reactivity towards glutathione (GSH). With this relationship, the objective of this study was to predict the GSH reactivity of dental methacrylate monomers, and hence their toxicity, using the ${ }^{13} \mathrm{C}$-NMR chemical shifts of $\beta$-carbon $\left(\delta_{\mathrm{C} \beta}\right)$ and the ${ }^{1} \mathrm{H}$-NMR shifts of the protons attached to $\beta$-carbon $\left(\delta_{\mathrm{Ha}}, \delta_{\mathrm{Hb}}\right)$. The different nucleophiles were chosen to compare the different nucleophilic reactions involving acrylate and methacrylate monomers. In conjunction with the use of literature data for monomer/GSH reactivity, significant linear relationships between GSH reactivity $(\log \mathrm{K})$ and $\delta_{\mathrm{C} \beta}$ or $\delta_{\mathrm{Ha}}$ were observed $(p<0.001)$. As for the oral $\mathrm{LD}_{50}$ values of some dental dimethacrylates in mice, they were estimated using linear regression curve fitting of GSH reactivity-toxicity response data. Results revealed an acceptable correlation between the oral $\mathrm{LD}_{50}$ values of acrylates and methacrylates and GSH reactivity $(p<0.05$, outlier: HEMA). In conclusion, the present findings suggested that NMR spectra might be useful for predicting the toxicity of dental methacrylates.
\end{abstract}

Keywords: Dental methacrylates, NMR spectra, Structure-activity relationships

Received Jun 9, 2009: Accepted Jul 24, 2009

\section{INTRODUCTION}

Methacrylate monomers are widely used in dentistry as denture base materials, lining materials, restorative resins, and bonding agents. However, methacrylate monomers generally do not polymerize completely in air because oxygen acts as a biradical and suppresses polymerization, leaving unreacted methacrylate groups on the resin surface ${ }^{1)}$. Consequently, unpolymerized methacrylates in dental materials play an inevitable role in causing irritation and allergic reactions in the oral cavity ${ }^{2,3}$. Depending on the lipophilicity (octanolwater partition coefficient, $\log \mathrm{P}$ ) of the monomers, they predominantly reside in the cell membranes of oral tissues. Apart from the lipophilicity factor, $\alpha, \beta$ unsaturated methacrylate esters used as resin monomers may exhibit toxicity through reaction with tissue nucleophiles via Michael addition ${ }^{4)}$ (Fig. 1).

Acrylates are known to have higher electrophilic reactivity than methacrylates, and have been previously reported to have high toxicity ${ }^{5-7)}$. The thiol group of glutathione (GSH) is often used as a model nucleophile, whereby the reaction rates of GSH $(\log \mathrm{K})$ have been used to investigate the quantitative structure-activity relationships (QSAR) of acrylates and methacrylates. This is because the reactivity of acrylates and methacrylates with sulfhydryl groups such as GSH and cysteine-containing polypeptides is closely related to their toxicity ${ }^{5,6)}$. Besides, methacrylates with $\alpha, \beta$-unsaturated carbonyl structures have been reported to possess allergenic properties due to their depletion of GSH ${ }^{8}$. In dentistry, the toxicity of triethylene glycol dimethacrylate (TEGDMA) has been shown to be related to its reactivity with $\mathrm{GSH}^{4,9}$, resulting in almost total depletion of intracellular GSH via Michael addition predominantly ${ }^{9}$.

According to spectral data, the reactivity of methacrylate monomers in polymerization and copolymerization reactions usually depends on the $\pi$ electron density on the double bond, particularly on the $\beta$-carbon. The higher the $\pi$-electron density of the $\beta$ carbon, the higher is the magnetic field where the NMR peak is observed, thus leading to a reduction in NMR chemical shift. On this premise, it becomes possible to correlate the magnitude of an NMR chemical shift with the reactivity of monomers via reactions such as Michael addition ${ }^{10)}$. Coupled with the availability of quantitative reactivity data for GSH with $\alpha, \beta$ unsaturated carbonyl compounds such as acrylates and methacrylates ${ }^{5-7)}$, the magnitudes of the NMR chemical shifts of $\beta$-carbons for methacrylate monomers may thus be used to estimate their GSH reactivity.

To clarify the mechanism of methacrylate-induced toxicity, a study ${ }^{11)}$ was undertaken to investigate the QSARs between the toxicity of acrylates and methacrylates against electronegativity ( $\chi$ term), NMR chemical shifts of $\beta$-carbons $\left(\delta_{\mathrm{C} \beta}\right)$, and $\log \mathrm{P}$. Findings of that study demonstrated acceptable QSARs for both $x$ and $\log \mathrm{P}$ terms ${ }^{11}$. However, the QSAR between GSH reactivity and NMR spectra for dental methacrylate monomers has not been investigated.

Against this backdrop of information scarcity, this study was undertaken to predict the GSH reactivity of dental methacrylate monomers using the ${ }^{13} \mathrm{C}-\mathrm{NMR}$ chemical shifts of $\beta$-carbon $\left(\delta_{\mathrm{C} \beta}\right)$ and the ${ }^{1} \mathrm{H}$-NMR chemical shifts of the protons attached to $\beta$-carbon $\left(\delta_{\mathrm{Ha}}\right.$ and $\delta_{\mathrm{Hb}}$ ). In addition, we investigated the QSAR 


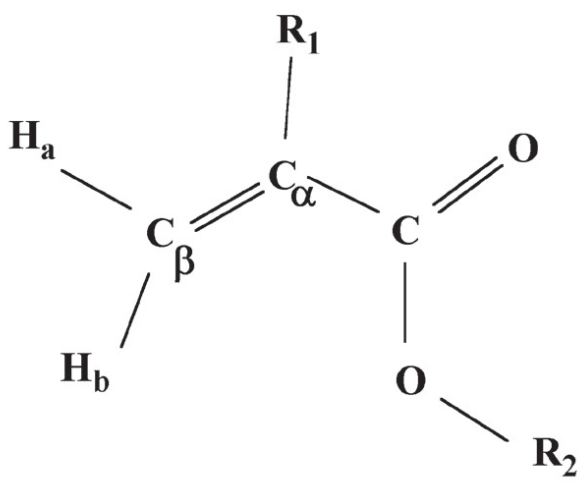

\section{$\mathrm{R}_{1}: \mathrm{H}$ for acrylates; $\mathrm{CH}_{3}$ for methacrylates}

\section{$\mathbf{R}_{2}$ : alcohol moiety}

Fig. 1 Structures of acrylates and methacrylates.

between GSH reactivity and acute toxicity exhibited by dental methacrylate monomers. The mechanisms underlying the toxicity of dental methacrylates were then discussed in light of this study's findings.

\section{MATERIALS AND METHODS}

\section{Monomers}

The monomers used in this study were methyl acrylate (MAA), ethyl acrylate (EAA), n-butyl acrylate (nBAA), isobutyl acrylate (iBAA), hexyl acrylate (HAA), 2ethylhexyl acrylate (2-EHAA), methyl methacrylate (MMA), ethyl methacrylate (EMA), isopropyl methacrylate (iPMA), n-butyl methacrylate (nBMA), isobutyl methacrylate (iBMA), $t$-butyl methacrylate (tBMA), allyl methacrylate (AllylMA), 2-hydroxyethyl methacrylate (HEMA), benzyl methacrylate (BZMA), ethylene glycol dimethacrylate (EGDMA), triethylene glycol dimethacrylate (TEGDMA), tetraethylene glycol dimethacrylate (tetraEGDMA), and 2,2-bis[4-(2hydroxy-3-methacryloyloxypropoxy)phenyl]propane (bis-GMA).

\section{NMR spectra}

The ${ }^{13} \mathrm{C}$-NMR and ${ }^{1} \mathrm{H}$-NMR chemical shift data for the different acrylate and methacrylate monomers in chloroform-d $\left(\mathrm{CDCl}_{3}\right)$ were adopted from Hatada et $a l{ }^{10)}$. Briefly, the chemical shifts of the selected monomers were measured in chloroform- $d$ at $35^{\circ} \mathrm{C}$ at 125 and/or $500 \mathrm{MHz}$, using tetramethylsilane (TMS) as an internal standard, as reported. Besides, the ${ }^{13} \mathrm{C}$ NMR chemical shifts of EGDMA, TEGDMA, and bisGMA were determined in $\mathrm{CDCl}_{3}$ using a JEOL Alpha500 NMR spectrometer ${ }^{11,12)}$, while the ${ }^{1} \mathrm{H}-\mathrm{NMR}$ chemical shift data for TEGDMA and bis-GMA were adopted from Vankerckhoven et al. ${ }^{13)}$.

\section{$G S H$ reactivity}

Three sets of data for the GSH reactivity of acrylates and methacrylates under cell-free conditions were taken from Tanii and Hashimoto ${ }^{14)}$, Freidig et al. ${ }^{6}$, and McCarthy et al. ${ }^{5}$. Briefly, the GSH solution was brought to $37^{\circ} \mathrm{C}$ and mixed with an equal volume of selected acrylates, methacrylates, or dimethacrylate also at $37^{\circ} \mathrm{C}$. Optical density was measured immediately at $412 \mathrm{~nm}$ using a spectrophotometer. From the loss of absorbance over time, the second-order rate constants $(\mathrm{K})$ were calculated ${ }^{6}$.

\section{Animal testing}

$\mathrm{LD}_{50}(50 \%$ lethal dose) data for intraperitoneal injection of mice with acrylate and methacrylate monomers were taken from Lawrence et al. ${ }^{15)}$. Briefly, male albino ICR mice weighing $25 \pm 5 \mathrm{~g}$ were used as test animals, and the $\mathrm{LD}_{50}$ dose for each compound was calculated for 7 day mortality. Data for the acute oral $\mathrm{LD}_{50}$ in male ddY mice $(24-27 \mathrm{~g})$ were taken from Weil ${ }^{16)}$. For the $\mathrm{LD}_{50}$ data of $\mathrm{EAA}^{17)}$, $\mathrm{MMA}^{18)}$, $\mathrm{BZMA}^{19)}$, AllylMA ${ }^{17)}$, nBMA $^{20)}$, TEGDMA ${ }^{21)}$, and bis-GMA ${ }^{22)}$ to be orally administered into rats, they were taken from the material safety data sheets of the respective agents.

\section{Multiple regression analysis}

The regression equations were derived using a StatMate III software program (ATMS Co. Ltd., Tokyo, Japan).

\section{RESULTS}

Prediction of GSH reactivity using ${ }^{13} \mathrm{C}$-NMR spectra

The GSH reactivity values of acrylates and methacrylates as measured in previous studies ${ }^{5,6,14)}$, as well as the calculated data (in the form of $\log \mathrm{K}_{1-4}$ ), are summarized in Tables 1 to 3 . For each acrylate or methacrylate monomer, their calculated data of $\log \mathrm{K}_{1}$, $\log \mathrm{K}_{2}, \log \mathrm{K}_{3}$, and $\log \mathrm{K}_{4}$ were obtained using Eq. (1), Eq. (2), Eq. (3), and Eq. (4) respectively (Table 4). As for Eq. (1), Eq. (2), Eq. (3), and Eq. (4), they were derived using the $K$ values of monomers observed in previous studies ${ }^{5,6,14)}$.

Michael addition has been proposed as the mechanism for the reaction of thiols with the unsaturated carboxylic esters of (meth)acrylates ${ }^{7)}$, and that the unsaturated $\beta$-carbon atom was most probably the site of attack. On this premise, the ${ }^{13} \mathrm{C}$-NMR chemical shift of $\beta$-carbon atom, $\delta_{\mathrm{C} \beta}$, was used as a descriptor to predict the GSH reactivity of (meth)acrylates. Table 1 shows the ${ }^{13} \mathrm{C}-\mathrm{NMR}$ chemical shifts of $\beta$-carbon and $\alpha$-carbon for 18 (meth)acrylates. Further, Fig. 1 shows the structure of (meth)acrylates for the assignment of ${ }^{1} \mathrm{H}$ - and ${ }^{13} \mathrm{C}-\mathrm{NMR}$ spectra.

The QSARs according to the published data of GSH reactivity in terms of $\delta_{\mathrm{C} \beta}$ were investigated, whereby the results are shown in Eqs. $1-3$ (Table 4). The ${ }^{13} \mathrm{C}$ NMR chemical shifts of $\delta_{\mathrm{C} \beta}$ and $\delta_{\mathrm{C} \alpha}$ for (meth)acrylates, particularly the former, were significantly correlated with their GSH reactivity $\left(\log \mathrm{K}_{1-3}\right) \quad(p<0.001)$. An 
Table $1 \quad{ }^{13} \mathrm{C}$-NMR chemical shifts of beta carbon $\left(\delta_{\mathrm{C} \beta}\right)$, alpha carbon $\left(\delta_{\mathrm{C} \alpha}\right)$, and the rate constants for the reaction with reduced glutathione (log $\mathrm{K})$ for (meth)acrylates

\begin{tabular}{|c|c|c|c|c|c|c|c|c|}
\hline \multirow[b]{3}{*}{ Compounds } & \multicolumn{2}{|c|}{ Chemical shifts ${ }^{a}$} & \multicolumn{6}{|c|}{$\log \mathrm{K}\left(\mathrm{M}^{-1} \mathrm{~s}^{-1}\right)$} \\
\hline & \multirow{2}{*}{$\begin{array}{c}\delta_{\mathrm{C} \beta} \\
\mathrm{ppm}\end{array}$} & \multirow{2}{*}{$\begin{array}{c}\delta_{\mathrm{C} \alpha} \\
\mathrm{ppm}\end{array}$} & \multicolumn{2}{|c|}{$\log \mathrm{K}_{1}$} & \multicolumn{2}{|c|}{$\log \mathrm{K}_{2}$} & \multicolumn{2}{|c|}{$\log \mathrm{K}_{3}$} \\
\hline & & & obsd $^{A}$ & pred $^{\mathrm{B}}$ & $\mathrm{obsd}^{\mathrm{C}}$ & pred $^{\mathrm{D}}$ & $\mathrm{obsd}^{\mathrm{E}}$ & pred $^{F}$ \\
\hline MAA & 130.56 & 128.15 & 1.6 & 1.0 & - & 1.1 & 1.7 & 1.9 \\
\hline EAA & 130.24 & 128.59 & 1.4 & 0.9 & 1.6 & 0.9 & 1.4 & 1.8 \\
\hline nBAA & 130.21 & 128.61 & 1.4 & 0.8 & - & 0.9 & 1.6 & 1.8 \\
\hline iBAA & 130.23 & 128.60 & 1.4 & 0.9 & 1.5 & 0.9 & - & 1.8 \\
\hline HAA & 130.23 & 128.63 & - & 0.9 & 1.3 & 0.9 & - & 1.8 \\
\hline 2-EHAA & 130.17 & 128.67 & - & 0.8 & - & 0.9 & - & 1.8 \\
\hline MMA & 125.2 & 136.2 & -0.7 & -1.0 & -0.7 & -1.1 & -0.5 & -0.3 \\
\hline EMA & 124.97 & 136.51 & -0.4 & -1.1 & - & -1.2 & -0.9 & -0.4 \\
\hline iPMA & 124.95 & 136.52 & -0.9 & -1.2 & - & -1.2 & - & -0.4 \\
\hline nBMA & 124.70 & 136.41 & -0.8 & -1.2 & -0.7 & -1.3 & - & -0.6 \\
\hline iBMA & 124.98 & 136.52 & -0.6 & -1.1 & - & -1.2 & - & -0.4 \\
\hline tBMA & 124.09 & 137.96 & -0.6 & -1.5 & - & -1.5 & - & -0.8 \\
\hline HEMA & 125.89 & 135.96 & -0.3 & -0.8 & - & -0.8 & - & -0.1 \\
\hline AllylMA & 125.46 & 136.23 & - & -1.0 & -0.3 & -0.9 & - & -0.2 \\
\hline BZMA & 125.66 & 136.21 & - & -0.9 & -0.5 & -0.9 & - & -0.1 \\
\hline EGDMA & 125.9 & 136.1 & - & -0.8 & - & -0.8 & -0.1 & 0.0 \\
\hline TEGDMA & 125.4 & 136.3 & - & -1.0 & - & -1.0 & - & 0.0 \\
\hline tetraEGDMA & - & - & - & - & - & - & 0.2 & - \\
\hline tetraEG* & - & - & - & - & - & - & 2.2 & - \\
\hline bis-GMA & 126.2 & 135.9 & - & -0.7 & - & -0.7 & - & 0.1 \\
\hline
\end{tabular}

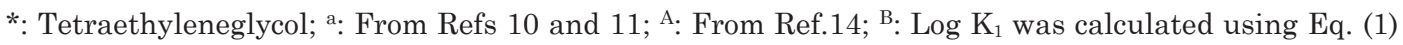
derived from 11 compounds shown in obst ${ }^{\mathrm{A}}$; ${ }^{\mathrm{C}}$ : From Ref. 6 ; ${ }^{\mathrm{D}}$ : Log $\mathrm{K}_{2}$ was calculated using Eq. (2) derived from 7 compounds shown in obst ${ }^{\mathrm{C}}$; ${ }^{\mathrm{E}}$ : From Ref. 5 ; ${ }^{\mathrm{F}}$ : Log $\mathrm{K}_{3}$ was calculated using Eq. (3) derived from 6 compounds shown in obst $\mathrm{t}^{\mathrm{E}}$.

See Table 4 for details on each equation.

acceptable dependence on both $\delta_{\mathrm{C} \beta}$ and $\delta_{\mathrm{C} \alpha}$ was observed, indicating that GSH reactivity might be associated with the $\alpha, \beta$-unsaturated carboxylic esters of (meth)acrylates. As a high correlation coefficient was observed for Eq. (1), namely $r^{2}=0.998, \delta_{\mathrm{C} \beta}$ was used to predict $K_{2}$ and $K_{3}$. The predicted log $K_{1-3}$ values for (meth)acrylates are shown in Table 1 . The high correlation coefficients suggested that it was thus feasible to predict GSH reactivity with methacrylates using NMR chemical shifts. Using Eqs (1) - (3), the GSH reactivity obtained in this study declined in the following order: acrylates (MAA, EAA, nBAA, iBAA, HAA, 2-EHAA) $>$ methacrylates with a functional group (HEMA, AllylMA, BZMA), dimethacrylates (EGDMA, TEGDMA, bis-GMA) > methacrylates (MMA, EMA, iPMA, nBMA, iBMA, tBMA). Acrylates were ranked as having the highest GSH reactivity, hence clearly suggesting the strong effect of the substitution pattern $(\mathrm{H})$ on the $\alpha$-carbon as compared to that $\left(\mathrm{CH}_{3}\right)$ on the $\alpha$-carbon for methacrylates (Fig.1).

Prediction of GSH reactivity using ${ }^{1} H-N M R$ spectra ${ }^{1} \mathrm{H}-\mathrm{NMR}$ chemical shifts are also affected by the $\pi$ electron density of the attached carbon. On this premise, we speculated that ${ }^{1} \mathrm{H}-\mathrm{NMR}$ chemical shifts could also be correlated with the reactivities of monomers, and hence could likewise serve as an important tool in the investigation of GSH reactivity with monomers. Although the chemical shift range for ${ }^{1} \mathrm{H}-\mathrm{NMR}$ is much smaller than that of ${ }^{13} \mathrm{C}-\mathrm{NMR}$, determination of ${ }^{1} \mathrm{H}-\mathrm{NMR}$ chemical shifts could be easier, more time-saving, and more convenient than with ${ }^{13} \mathrm{C}$-NMR. On this premise, we investigated the QSARs using ${ }^{1} \mathrm{H}-\mathrm{NMR}$ chemical shifts. 
Table $2 \quad{ }^{1} \mathrm{H}-\mathrm{NMR}$ chemical shifts $\left(\delta_{\mathrm{Ha}}, \delta_{\mathrm{Hb}}\right)$, chemical shift differences between $\delta_{\mathrm{Ha}}$ and $\delta_{\mathrm{Hb}}\left(\Delta\left|\delta_{\mathrm{Ha}}-\delta_{\mathrm{Hb}}\right|\right)$, and rate constants for the reaction with reduced glutathione $\left(\log \mathrm{K}_{4}\right)$ for (meth)acrylates

\begin{tabular}{|c|c|c|c|c|c|}
\hline \multirow[b]{2}{*}{ Compounds } & \multicolumn{3}{|c|}{ NMR chemical shifts (ppm) ${ }^{a}$} & \multicolumn{2}{|c|}{$\log \mathrm{K}_{4}\left(\mathrm{~mol}^{-1} \mathrm{~min}^{-1}\right)$} \\
\hline & $\delta_{\mathrm{Ha}}$ & $\delta_{\mathrm{Hb}}$ & $\Delta\left|\delta_{\mathrm{Ha}}-\delta_{\mathrm{Hb}}\right|$ & $\mathrm{obsd}^{\mathrm{A}}$ & $\operatorname{pred}^{\mathrm{B}}$ \\
\hline MAA & 5.825 & 6.406 & 0.581 & 1.60 & 1.52 \\
\hline EAA & 5.807 & 6.395 & 0.588 & 1.43 & 1.39 \\
\hline nBAA & 5.805 & 6.391 & 0.586 & 1.40 & 1.37 \\
\hline iBAA & 5.813 & 6.400 & 0.587 & 1.62 & 1.45 \\
\hline HAA & 5.804 & 6.391 & 0.587 & $1.31^{\mathrm{d})}$ & 1.36 \\
\hline 2-EHAA & 5.806 & 6.385 & 0.579 & - & 1.40 \\
\hline MMA & 5.550 & 6.100 & 0.545 & -0.68 & -0.60 \\
\hline EMA & 5.541 & 6.096 & 0.555 & -0.40 & -0.66 \\
\hline nBMA & 5.532 & 6.091 & 0.559 & -0.77 & -0.75 \\
\hline iBMA & 5.543 & 6.108 & 0.565 & -0.63 & -0.65 \\
\hline HEMA & 5.601 & 6.149 & 0.548 & -0.27 & -0.20 \\
\hline AllylMA & 5.574 & 6.138 & 0.564 & $-0.29^{\mathrm{d})}$ & -0.41 \\
\hline BZMA & 5.572 & 6.153 & 0.581 & $-0.49^{\mathrm{d})}$ & -0.42 \\
\hline TEGDMA $^{\text {b) }}$ & 5.56 & 6.10 & 0.54 & - & -0.52 \\
\hline bis-GMA ${ }^{\text {b) }}$ & 5.56 & 6.10 & 0.54 & - & -0.52 \\
\hline bis-GMA ${ }^{c}$ & 5.60 & 6.14 & 0.54 & - & -0.21 \\
\hline TEGDMA') & 5.56 & 6.13 & 0.57 & & \\
\hline
\end{tabular}

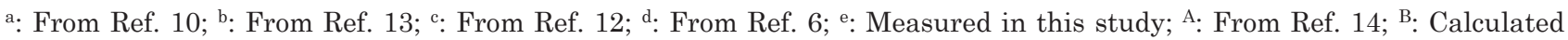
using Eq. (4) derived from 12 compounds shown in obst ${ }^{\mathrm{A}}$.

For details on Eq. (4), see Table 4.

As shown in Fig. 1, $\mathrm{H}_{\mathrm{a}}$ and $\mathrm{H}_{\mathrm{b}}$ represent the protons trans and cis respectively as the substituents on the ester moiety. The chemical shifts of $\mathrm{H}_{\mathrm{a}}\left(\delta_{\mathrm{Ha}}\right)$ and $\mathrm{H}_{\mathrm{b}}\left(\delta_{\mathrm{Hb}}\right)$, and the shift difference between $\delta_{\mathrm{Ha}}$ and $\delta_{\mathrm{Hb}}$ for the selected (meth)acrylates are shown in Table 2. Further in Table 4, Eq. (4) demonstrated that an acceptable QSAR was found for GSH reactivity (log $\mathrm{K}_{4}$ ) and $\delta_{\mathrm{Ha}}$. The correlation coefficient for $\delta_{\mathrm{Ha}}$ was similar to that for $\delta_{\mathrm{Hb}}$ (data not shown). Regarding the correlation coefficient for the shift difference between $\delta_{\mathrm{Ha}}$ and $\delta_{\mathrm{Hb}}$, it was smaller than that for $\delta_{\mathrm{Ha}}$ or $\delta_{\mathrm{Ha}}$. Owing to the high correlation coefficient observed for Eq. (4), the latter was used to predict the GSH reactivity $\left(\log \mathrm{K}_{4}\right.$ ) for 16 selected monomers and their data are shown in Table 2.

The predicted $\log \mathrm{K}_{4}$ values for (meth)acrylates were shown to decline in the following order: acrylates (MAA, EAA, nBAA, iBAA, HAA, 2-EHAA) > methacrylates with a functional group (HEMA, AllylMA, BZMA), dimethacrylates (EGDMA, TEGDMA, bis-GMA) > methacrylates (MMA, EMA, nBMA, nBMA, iBMA). The order of reactivity was similar to that obtained using ${ }^{13} \mathrm{C}$-NMR spectra. In other words, apart from ${ }^{13} \mathrm{C}$-NMR chemical shifts, ${ }^{1} \mathrm{H}-\mathrm{NMR}$ chemical shifts are similarly useful for the prediction of GSH reactivity.

QSAR between acute toxicity and GSH reactivity

Detoxication of acrylates and methacrylates involves conjugation with GSH, whereby chemical reactivity leading to GSH depletion has been reported as a cause for the acute toxicity of acrylates and methacrylates ${ }^{5,6}$. Using five acrylates and five methacrylates, we investigated the relationship between $\mathrm{LD}_{50}$ in mice and GSH reactivity $\left(\log \mathrm{K}_{1-4}\right)$. The results shown in Table 3 indicated that the acute toxicity exhibited by (meth)acrylates in ICR mice was about 10-fold greater than that in ddY mice. This vast disparity might be caused by the different toxicity testing methods employed in this study: the $\mathrm{LD}_{50}$ values in ICR mice were obtained by intraperitoneal injection, whereas it was by oral administration for ddY mice.

Table 4 shows the QSARs between GSH reactivity $\left(\log \mathrm{K}_{1}, \log \mathrm{K}_{4}\right)$ and acute toxicity $\left(\mathrm{LD}_{50}\right)$ in mice. Except for HEMA, the intraperitoneal $\mathrm{LD}_{50}$ values in ICR mice were highly correlated with $\log \mathrm{K}_{1}$ or $\mathrm{K}_{4}\left(r^{2} \approx\right.$ $0.8, p<0.01)$. In contrast, the oral $\mathrm{LD}_{50}$ values in $\mathrm{ddY}$ mice were slightly but nonetheless significantly correlated with $\log \mathrm{K}_{1}$ or $\mathrm{K}_{4}\left(r^{2} \approx 0.5, p<0.05\right)$. On the different toxicity testing methods used, a linear 
Table 3 The observed and predicted values for 50\% lethal dose $\left(\mathrm{LD}_{50}\right)$, and $\log \mathrm{P}$ (octanol-water partition coefficient) for (meth)acrylates

\begin{tabular}{|c|c|c|c|c|c|c|}
\hline \multirow[b]{4}{*}{ Compounds } & \multirow[b]{4}{*}{$\log \mathrm{P}^{\mathrm{a})}$} & \multicolumn{2}{|c|}{$\left.\mathrm{LD}_{50} \mathrm{~b}\right)$} & \multicolumn{2}{|c|}{$\mathrm{LD}_{50}^{\mathrm{a})}$} & \multirow[b]{3}{*}{ Oral rat $\mathrm{LD}_{50}{ }^{\mathrm{c})}$} \\
\hline & & \multicolumn{2}{|c|}{ Intraperitoneal ICR mice } & \multicolumn{2}{|c|}{ Oral ddY mice } & \\
\hline & & Obsd & Pred $^{\mathrm{A}}$ & Obsd & Pred $^{\mathrm{B}}$ & \\
\hline & & $\mathrm{mmol} / \mathrm{kg}$ & $\mathrm{mmol} / \mathrm{kg}$ & $\mathrm{mmol} / \mathrm{kg}$ & $\mathrm{mmol} / \mathrm{kg}$ & $\mathrm{mmol} / \mathrm{kg}$ \\
\hline MAA & 0.80 & 2.95 & 5.5 & 9.60 & 29.4 & - \\
\hline EAA & 1.33 & 5.99 & 5.8 & 17.97 & 51.4 & $<50^{\mathrm{e})}$ \\
\hline nBAA & 2.36 & 6.65 & 5.8 & 58.98 & 85.5 & - \\
\hline iBAA & 2.22 & 5.93 & 5.7 & 47.63 & 85.1 & - \\
\hline 2-EHAA & $3.72^{\mathrm{b})}$ & 7.20 & 5.8 & - & - & \\
\hline MMA & 1.38 & 11.22 & 10.3 & 51.97 & 69.4 & $79.9^{\mathrm{d})}$ \\
\hline EMA & 1.94 & 10.90 & 10.4 & 68.64 & 107.3 & - \\
\hline nBMA & 2.88 & 10.48 & 10.6 & 142.70 & 144.6 & $113^{\mathrm{f}}$ \\
\hline iBMA & 2.66 & 8.94 & 10.4 & 83.14 & 134.6 & - \\
\hline HEMA & 0.47 & 4.06 & 9.4 & 45.24 & - & - \\
\hline AllylMA & 1.57 & - & 9.8 & - & 90.3 & $2.8-5.1^{\mathrm{e})}$ \\
\hline BZMA & 2.53 & - & 9.9 & - & 125.4 & $28.4^{\mathrm{g})}$ \\
\hline TEGDMA & $1.55^{\mathrm{h})}$ & - & 11.2 & - & 89.7 & $37.9^{\mathrm{i})}, 37.6(\text { mice })^{\mathrm{i})}$ \\
\hline bis-GMA & $5.07^{\mathrm{h})}$ & - & 10.1 & - & 218.2 & $>9.3^{\mathrm{j})}$ \\
\hline
\end{tabular}

A: Predicted using Eq. (9) derived from the observed values (Obsd) for 9 compounds except HEMA; B: Predicted using Eq.

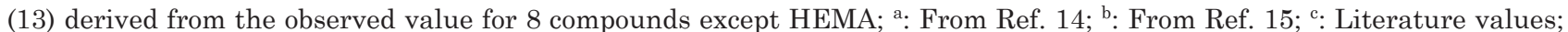

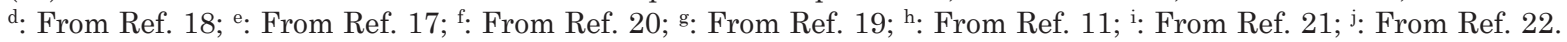

Table 4 Quantitative structure-activity relationships (QSARs) between: (A) reduced glutathione GSH reactivity (log $\mathrm{K}_{1}$, $\mathrm{K}_{2}, \mathrm{~K}_{3}$, or $\left.\mathrm{K}_{4}\right)$ and NMR-chemical shifts $\left(\delta_{\mathrm{C} \beta}, \delta_{\mathrm{C \alpha}}, \delta_{\mathrm{Ha}}, \delta_{\mathrm{Hb}}\right.$ or $\left.\Delta\left|\delta_{\mathrm{Ha}}-\delta_{\mathrm{Hb}}\right|\right)$; and (B) between $\mathrm{LD}_{50}(50 \%$ lethal dose) and descriptors $\left(\log \mathrm{K}_{1}, \log \mathrm{K}_{4}, \log \mathrm{P}\right)$ for (meth)acrylates

A)

$\log \mathrm{K}_{1}=-48.6( \pm 0.2)+0.4( \pm 0.0) \delta_{\mathrm{CB}}\left(n=11, r^{2}=0.998, p<0.001\right)$

Eq. (1)

$\log \mathrm{K}_{2}=-51.2( \pm 0.1)+04( \pm 0.0) \delta_{\mathrm{CB}}\left(n=7, r^{2}=0.99, p<0.001\right)$

Eq. (2)

$\log \mathrm{K}_{3}=-52.9( \pm 0.2)+04( \pm 0.0) \delta_{\mathrm{CB}}\left(n=6, r^{2}=0.85, p<0.001\right)$

Eq. (3)

$\log \mathrm{K}_{4}=-43.5( \pm 0.1)+7.7( \pm 0.3) \delta_{\mathrm{Ha}}\left(n=12, r^{2}=0.99, p<0.001\right)$

Eq. (4)

$\log \mathrm{K}_{4}=-27.5( \pm 0.6)+48.6( \pm 12.5)\left|\delta_{\mathrm{Ha}}-\delta_{\mathrm{Hb}}\right|\left(n=12, r^{2}=0.63, p<0.01\right)$

Eq. (5)

B)

$\mathrm{LD}_{50}{ }^{*}=9.1( \pm 2.2)-1.9( \pm 0.7) \log \mathrm{K}_{1} \quad\left(n=10, r^{2}=0.48, p<0.05\right)$

Eq. (6)

$\mathrm{LD}_{50}{ }^{*}=9.9( \pm 2.1)-1.7( \pm 0.7) \log \mathrm{K}_{4} \quad\left(n=10, r^{2}=0.48, p<0.05\right)$

Eq. (7)

$\mathrm{LD}_{50}{ }^{*}=10.4( \pm 1.3)-2.2( \pm 0.5) \log \mathrm{K}_{1}$ (outlier: HEMA, $n=9, r^{2}=0.80, p<0.01$ )

Eq. (8)

$\mathrm{LD}_{50}{ }^{*}=8.9( \pm 2.1)-2.3( \pm 0.7) \log \mathrm{K}_{4} \quad$ (outlier: HEMA, $n=9, r^{2}=0.8, p<0.01$ )

Eq. (9)

$\mathrm{LD}_{50}{ }^{\#}=60( \pm 30.9)-27.7( \pm 10.6) \log \mathrm{K}_{1}$ (outlier: HEMA, $\left.n=8, r^{2}=0.52, p<0.05\right)$

Eq. (10)

$\mathrm{LD}_{50}{ }^{\#}=-4.8( \pm 27.1)+435.5( \pm 11.5) \log \mathrm{P} \quad\left(n=9, r^{2}=0.58, p<0.05\right)$

Eq. (11)

$\mathrm{LD}_{50}^{\#}=70.2( \pm 31.4)-26.1( \pm 10.6) \log \mathrm{K}_{4}\left(\right.$ outlier: HEMA, $\left.n=8, r^{2}=0.55, p<0.05\right)$

Eq. (12)

$\mathrm{LD}_{50}{ }^{\#}=15.1( \pm 17.3)+37.9(10.1) \log \mathrm{P}-16.4( \pm 6.7) \log \mathrm{K}_{1}$

(outlier: HEMA, $n=8, r^{2}=0.88, p<0.01$ )

Eq. (13)

For more details on $\log \mathrm{K}_{1-4}$ and $\mathrm{LD}_{50}$, see Tables $1-3$, respectively.

$\mathrm{LD}_{50}{ }^{*}$ in intraperitoneal ICR mice. $\mathrm{LD}_{50}{ }^{\#}$ in oral ddY mice. 
relationship was observed between the two sets of $\mathrm{LD}_{50}$ values (intraperitoneal versus oral), but with a poor correlation $\left(n=9, r^{2}=0.457, p<0.05\right)$.

In general, the acute toxicity of (meth)acrylates is correlated with their $\log \mathrm{P}$ term ${ }^{14,15)}$. In the present study, oral $\mathrm{LD}_{50}$ was significantly correlated with the $\log \mathrm{P}$ term as shown in Eq. (11), whereas there was no correlation between intraperitoneal $\mathrm{LD}_{50}$ and the $\log \mathrm{P}$ term. This contrast in toxic response $\left(\mathrm{LD}_{50}\right)$ might be caused by discrepancies in the $\log \mathrm{P}$ function of the monomers under different toxicity testing methods (intraperitoneal versus oral). The $\log \mathrm{K}$ term of a monomer is related to the latter's interaction with the relevant receptor(s), whereas the log $\mathrm{P}$ term is related to a monomer's penetration into the site of action ${ }^{11,14,15)}$.

Interestingly, oral $\mathrm{LD}_{50}$ in ddY mice showed a more acceptable QSAR in terms of both $\log \mathrm{K}_{1}$ and $\log \mathrm{P}$ in Eq. (13) $\left(r^{2}=0.88, p<0.01\right.$, outlier: HEMA), as compared with only $\log \mathrm{K}_{1}$ in Eq. (10) and $\log \mathrm{P}$ in Eq. (11). On this premise, Eq. (13) was used to predict the oral $\mathrm{LD}_{50}$ values for the (meth)acrylates and the data are shown in Table 3. In addition, the predicted $L D_{50}$ values in mice for EAA, MMA, nBMA, BZMA, AllylMA, TEGDMA, and bis-GMA were compared against those reported in the literature for rats via the oral route (Table 3). Upon comparison, it was found that the oral $\mathrm{LD}_{50}$ values for EAA, MMA, and TEGDMA in mice were similar to those in rats (Table 3). However, the predicted oral $\mathrm{LD}_{50}$ values for AllylMA and bis-GMA in rats were about 20 -fold greater than those in mice. Similarly, the oral $\mathrm{LD}_{50}$ values for nBMA and BZMA in rats were about 4 -fold greater than those in mice. The high toxicity levels of AllylMA and bis-GMA might be related to their hydrolysis products and/or metabolized intermediates in addition to differences stemming from the animal species and toxicity testing methods employed.

\section{DISCUSSION}

Based on the results obtained in this study, it was shown that GSH reactivity with acrylates, methacrylates, and dimethacrylates was significantly correlated with their NMR chemical shifts. Although the chemical shift range of ${ }^{1} \mathrm{H}$-NMR was smaller than that of ${ }^{13} \mathrm{C}-\mathrm{NMR}$, the spectra of both ${ }^{13} \mathrm{C}$ - and ${ }^{1} \mathrm{H}$-NMR were used as descriptors in this study to predict the GSH reactivity of monomers. Results revealed that GSH reactivity declined in the following order: acrylates $>>$ methacrylates with a functional group: hydroxyl, benzyl, or allyl substituent (ester group) > dimethacrylates $>$ methacrylates with a short-chain aliphatic substituent (ester group). In previous studies $^{6,23)}$, acrylates such as EAA and iBAA were reported to exhibit markedly greater toxicity than methacrylates such as MMA and iPMA in fathead minnow or mice. Taking into consideration the results of the present study and those of published literature ${ }^{6,23)}$, it could be claimed that acrylates with a high GSH reactivity showed higher toxicity than methacrylates with a low GSH reactivity.

On the other hand, AllylMA showed lower GSH reactivity than EAA and BBAA although it exhibited higher toxicity than the latter acrylates ${ }^{22}$. In a previous study ${ }^{24)}$, this anomaly was attributed to the hydrolysis products and/or metabolized intermediates of AllylMA. The hydrolysis of AllylMA produced allyl alcohol, and that toxicity was caused by the oxidation/ metabolism of allyl alcohol by alcohol dehydrogenase in the liver to the highly reactive acrolein. In the present study, the predicted $\mathrm{LD}_{50}$ for AllylMA was similar to that for BAA, further confirming that the strong toxicity of AllyMA in animal tests could be related to its hydrolysis products.

For HEMA bearing a hydroxyl substituent, its intraperitoneal $\mathrm{LD}_{50}$ value in mice was higher than those for nBAA and iBAA $^{13)}$, although the GSH reactivity of the former was lower than the latter two. Similarly, this could be attributed to a hydrolysis product of HEMA, namely ethylene glycol. Ethylene glycol is then metabolized by liver alcohol dehydrogenase to glycolaldehyde, which in turn is rapidly metabolized to glycolate - a toxic metabolite. The toxicity of ethylene glycol is complex and not fully understood, chiefly due to the severe metabolic acidosis caused by glycolate ${ }^{25}$.

For the methacrylate monomers investigated in this study, the results obtained suggested that their toxicity might be influenced by the hydrolysis and/or metabolic products derived from the original parent monomers. For example, the relatively high acute toxicity of EGDMA (oral $\mathrm{LD}_{50}$ in mice: about $10 \mathrm{mmol} /$ $\mathrm{kg}^{26)}$ ) could be related to its hydrolysis products namely, methacrylic acid, HEMA, and ethylene glycol. On the same note, the GSH reactivity of BZMA, an aromatic methacrylate, was greater than that of aliphatic methacrylates. This could be chiefly due to a hydrolysis product derived from BZMA, benzyl alcohol, an alcohol moiety which was reported to be of toxicological importance because benzyl alcohols seemed to exhibit toxicity via a radical mechanism ${ }^{27)}$. Further, while similar $\mathrm{LD}_{50}$ values were predicted for BZMA and BMA in the present study, disparity was found between the predicted and experimental data of BZMA. The latter finding could be attributed to the hydrolysis of BZMA, because its hydrolysis products were not taken into account when the toxicity of this compound was predicted using QSAR.

For the dimethacrylates EGDMA and TEGDMA, their GSH reactivity was similar to that of HEMA. It has been found in previous studies that TEGMA depletes intracellular GSH and interferes with cellular metabolism ${ }^{9,28)}$. This is chiefly because the hydrolysis of TEGDMA produces triethylene glycol and methacrylic acid, and triethylene glycol might have exhibited reactivity toward GSH. As shown in Table 1, tetraethylene glycol exhibited markedly higher GSH reactivity than tetraethylene glycol dimethacrylate $(\text { tetraEGDMA) })^{5}$. This suggested that the ethylene glycol oligomers - namely, diethylene glycol, 
triethylene glycol, and tetraethylene glycol - derived from the hydrolysis of the corresponding dimethacrylates might have played a larger and more active role in acute toxicity than the original dimethacrylates bearing ethylene glycol groups.

For bis-GMA, it is a reaction product of methacrylic acid and diglycidyl ether of bisphenol A. Upon enzymatic or chemical-induced hydrolysis, it yields the following products ${ }^{29,30)}$ : methacrylic acid, (2[4-(2,3-dihydroxypropoxy)phenyl]-2-[4-(2-hydroxy-3methacryloxypropoxy) phenyl]propane), 2,2'-bis[4-(2,3dihydroxypropoxy)phenyl]propane (BHP), and 2-(4hydroxyphenyl)-2-[4-(2,3-dihydroxypropoxy)phenyl] propane. In the present study, bis-GMA was predicted to have a low toxicity at $218 \mathrm{mmol} / \mathrm{kg}$ (Table 3). However, animal testing via intraperitoneal injection yielded a relatively high toxicity at about $10 \mathrm{mmol} / \mathrm{kg}^{222}$. Therefore, while it was reported on one hand that apoptosis or cell death was induced by the metabolic oxidation of a single terminal hydroxyl group of the parent $\mathrm{glycol}^{2}$, the relatively high toxicity of bis-GMA was probably attributed to its hydrolytic metabolites.

In light of the findings of the present study, acceptable relationships were found for the NMR chemical shifts $\left(\delta_{\mathrm{C} \beta}\right.$ and $\delta_{\mathrm{Ha}}$ ) and GSH reactivity (log K) of (meth)acrylates. MMA-induced depletion of GSH and oxidized glutathione (GSSG) in rat liver and kidney has been previously reported ${ }^{31}$. In this study, the probability of causable relationships between acute toxicity and the GSH reactivity (log K) of (meth)acrylates ${ }^{5,6,14)}$ further suggested that the detoxication of (meth)acrylates might be related to in vivo GSH and GSSG depletion. In other words, the NMR chemical shifts of the $\alpha, \beta$-unsaturated carboxylic esters of methacrylate monomers could be used as a means to measure and predict their acute toxicity in addition to the $\log \mathrm{P}$ term.

\section{CONCLUSIONS}

Based on the published data for GSH reactivity, acute toxicity, and NMR spectra of acrylate and methacrylate monomers, QSAR studies were carried out. It was found that the GSH reactivity of (meth)acrylates was significantly related to their ${ }^{13} \mathrm{C}-\mathrm{NMR}$ spectra $\left(\delta_{\mathrm{C} \beta}\right)$ and ${ }^{1} \mathrm{H}-\mathrm{NMR}$ spectra $\left(\delta_{\mathrm{Ha}}\right.$ and $\left.\delta_{\mathrm{Hb}}\right)$. This meant that the NMR spectra of (meth)acrylates could be used to predict their toxicity because there was an acceptable correlation between GSH reactivity and acute toxicity. However, there were discrepancies between the predicted and experimental data, hence suggesting that metabolic alterations of the original monomers might affect in vivo toxicity.

\section{REFERENCES}

1) Vankerckhoven H, Lambrechts $P$, van Beylen M, Davidson CL, Vanherle G. Unreacted methacrylate groups on the surfaces of composite resins. J Dent Res 1982; 60: 791-795.

2) Schweikl H, Spagnuolo G, Schmalz G. Genetic and cellular toxicology of dental resin monomers. J Dent Res 2006; 85: 870-877.

3) Aalto-Korte K, Alanko K, Kuuliala O, Jolanki R. Methacrylate and acrylate allergy in dental personnel. Contact Dermatitis 2007; 57: 324-330.

4) Geurtsen W, Leyhausen G. Chemical-biological interactions of the resin monomer triethyleneglycol dimethacrylate (TEGDMA). J Dent Res 2001; 80: 2046-2050.

5) McCarthy TJ, Hayes EP, Schwartz CS, Witz G. The reactivity of selected acrylate esters toward glutathione and deoxyribonucleosides in vitro: Structure-activity relationships. Fundam Appl Toxicol 1994; 22: 543-548.

6) Freidig AP, Verhaar HJM, Hermens JLM. Quantitative structure-property relationships for the chemical reactivity of acrylates and methacrylates. Environ Toxicol Chem 1999; 18: 1133-1139.

7) Yarbrough JW, Schultz TW. Abiotic sulfhydryl reactivity: a predictor of aquatic toxicity for carbonyl-containing alpha, beta-unsaturated compounds. Chem Res Toxicol 2007; 20: 558-562.

8) Ahlfors SR, Sterner O, Hansson C. Reactivity of contact allergenic haptens to amino acid residues in a model carrier peptide, and characterization of formed peptide-hapten adducts. Skin Pharmacol Appl Skin Physiol 2003; 16: 5968.

9) Volk J, Engelmann J, Leyhausen G, Geurtsen W. Effects of three resin monomers on the cellular glutathione concentration of cultured human gingival fibroblasts. Dent Mater 2006; 22: 499-505.

10) Hatada K, Kitayama T, Nishiura T, Shibuya W. Relation between reactivities of vinyl monomers and their NMR spectra. Current Org Chem 2002; 6: 121-153.

11) Ishihara M, Fujisawa S. A structure-activity relationship study on the mechanisms of methacrylate-induced toxicity using NMR chemical shift of $\beta$-carbon, RP-HPLC $\log \mathrm{P}$ and semiempirical molecular descriptor. Dent Mater J 2009; 28: 113-120.

12) Fujisawa S. Nuclear magnetic resonance spectra of bis-GMA and iso-bis-GMA. Dent Mater J 1994; 13: 251-255.

13) Vankerckhoven H, Lambrechts $P$, van Beylen M, Vanherle G. Characterization of composite resins by NMR and TEM. J Dent Res 1981; 60: 1957-1965.

14) Tanii H, Hashimoto K. Structure-toxicity relationship of acrylates and methacrylates. Toxicol Lett 1982; 1: 125-129.

15) Lawrence WH, Bass GE, Purcell WP, Autian J. Use of mathematical models in the study of structure-toxicity relationships of dental compounds. I. Esters of acrylic and methacrylic acids. J Dent Res 1972; 51: 526-535.

16) Weil CS. Tables for convenient calculation of median effective dose $\left(\mathrm{LD}_{50}\right.$ or $\left.\mathrm{ED}_{50}\right)$ and instructions in their use. Biometrics 1952; 8: 249-263.

17) Material Safety Data Sheet. Ethyl acrylate, allyl methacrylate MSDS, ARKEMA Canada Inc., Canada, 2007

18) Material Safety Data Sheet. Methyl methacrylate MSDS, Catalog No.18800, Electron Microscopy Science (EMS), PA, USA, 2006.

19) Material Safety Data Sheet. Benzyl methacrylate MSDS, Physical and Theoretical Chemistry Laboratory, Oxford University, England, 2005.

20) Material Safety Data Sheet. n-Butyl methacrylate MSDS, ScienceLab.com, Texas, USA, 2008.

21) Material Safety Data Sheet. Triethylene glycol dimethacrylate MSDS, Sigma-Aldrich, Germany,1995.

22) Schmalz G. The biocompatibility of non-amalgam dental filling materials. Eur J Oral Sci 1998;106: 696-706.

23) Karabunarliev S, Mekenyan OG, Karcher W, Russom CL, Bradbury SP. Quantum-chemical descriptors for estimating the acute toxicity of electrophiles to the fathead minnow (pimephales promelas): An analysis based on molecular 
mechanisms. Quant Struct-Act Relat 1996; 15: 302-310.

24) Ohno Y, Jones TW, Ormstad K. Allyl alcohol toxicity in isolated renal epithelial cells: protective effects of low molecular weight thiols. Chem Biol Interact 1985; 52: 289299.

25) Jacobsen D, McMartin KE. Methanol and ethylene glycol poisonings: mechanism of toxicity, clinical course, diagnosis and treatment. Med Toxicol 1986; 1: 309-334.

26) Freidig A, Hofhuis M, van Holstijn I, Hermens J. Glutathione depletion in rat hepatocytes: a mixture toxicity study with $\alpha, \beta$-unsaturated esters. Xenobiotica 2001; 31: 295-307.

27) Kapur S, Shusterman A, Verma RP, Hansch C, Selassi CD. Toxicology of benzyl alcohols: a QSAR analysis. Chemosphere 2000; 41: 1643-1649.
28) Engelmann J, Leyhausen G, Leibfritz D, Geurtsen W Metabolic effects of dental resin components in vitro detected by NMR spectroscopy. J Dent Res 2001; 80: 869875.

29) Kostoryz EL, Eick JD, Glaros AG, Judy BM, Welshons WV, Burmaster S, Yourtee DM. Biocompatibility of hydroxylated metabolites of BISGMA and BFDGE. J Dent Res 2003; 82: 367-371.

30) Kadoma Y, Tanaka M. Acid and base-catalyzed hydrolysis of bisphenol A-related compounds. Dent Mater J 2000; 19: 139-152.

31) Elovaara E, Kivistö H, Vainio H. Effects of methyl methacrylate on non-protein thiols and drug metabolizing enzymes in rat liver and kidneys. Arch Toxicol 1983; 52: 109-121. 